\title{
Incidência da oscilação postural em adultos jovens com cefaleia
}

\author{
Juliana Barros Freire ${ }^{(D)}$, Amanda de Oliveira Toledo ${ }^{(D)}$, Ana Maria Moreno Marinho ${ }^{(D)}$, \\ Aretha de Magalhães e Souza ${ }^{(D)}$, Lorena Amaral Moreira ${ }^{(D)}$, Ticiana Mesquita de Oliveira Fontenele (iD), \\ Maíra de Oliveira Viana Rela
}

Universidade de Fortaleza, Fortaleza, Ceará, Brasil.

\section{Introdução}

A cefaleia é uma das doenças mais prevalentes e o segundo agravo de saúde mais comum da população mundial. Entre as alterações relacionadas à dor de cabeça, o desequilíbrio postural vem sendo associado à cefaleia devido à hiperatividade da musculatura cervical alterando o centro gravitacional.

\section{Objetivos}

Avaliar a presença de oscilação postural em adultos jovens diagnosticados com cefaleia.

\section{Material e métodos}

Trata-se de um estudo transversal, com abordagem quantitativa, realizado no setor de Fisioterapia do Núcleo de Atenção Médica Integrada com o parecer ético $n^{\circ} 4.618 .892$. Foram inclusos pacientes de ambos os sexos, com idade a partir dos 18 anos, com diagnóstico de cefaleia e sem a presença de distúrbios neurológicos centrais ou periféricos. Para mensurar o impacto da dor de cabeça e da funcionalidade aplicou-se o questionário Questionário Headache Impact Teste (HIT) e por fim, foi utilizado o baropodômetro Footwork Pro $®$ e a plataforma guiada pelo programa Footwork. Para analisar a estabilometria, o paciente foi orientado a subir descalço na plataforma, relaxar os braços ao longo do corpo e manter os olhos fechados durante 10 segundos.

\section{Resultados}

A amostra foi composta por 42 pacientes, sendo com maior predominância o sexo feminino com 85,7\% ( $n=36$ ) com média de idade 30,6 ( $\pm 12,9)$ anos. Em relação as características da cefaleia $71,4 \%(n=30)$ relataram dor de intensidade moderada, uma média de 7,02 $\pm 6,44$ de crises por mês e 5,7 $\pm 6,2$ anos com cefaleia. Na estabilometria foi observado uma oscilação anteroposterior de olhos abertos $2,2 \pm 1,6 \mathrm{~cm}$ e latero-lateral de 1,8 $\pm 1,7 \mathrm{~cm}$ e de olhos fechados anteroposterior $2,7 \pm 1,2 \mathrm{~cm}$ e latero-lateral 1,7 $\pm 0,9 \mathrm{~cm}$. Esses dados foram analisados pelo programa SPSS statistic 20.0.

\section{Conclusão}

Foi possivel observar a predominância de cefaleia no sexo feminino com intensidade de dor classificada como moderada e obtendo uma maior oscilação postural anteroposterior na análise de olhos fechados.

Palavras-chave: Cefaleia; Desequilíbrio postural; Dor. 